\title{
Models in active learning in schools
}

\author{
Tulus $^{1 *}$, Muhammad Zarlis ${ }^{2}$, Sawaluddin ${ }^{1}$, M.R. Syahputra ${ }^{1}$, T.J. Marpaung ${ }^{1}$ \\ ${ }^{1}$ Department of Mathematics, Universitas Sumatera Utara, Medan, Indonesia \\ ${ }^{2}$ Department of Information Technology, Universitas Sumatera Utara, Medan, Indonesia \\ *Email: tulus@usu.ac.id
}

\begin{abstract}
The model is part of a learning structure that has a scope large. Inside there are approaches, strategies, methods, and techniques. One of an important aspect of a learning model is syntax, which is standard steps that must be taken in implementing the model. This syntax should be reflected in the steps of learning in particular detailed in the core learning activities. The results achieved in this activity are the teacher has the ability to develop scenarios or core steps active learning that uses certain learning models through the use of supporting media in teaching and learning activities
\end{abstract}

Keyword: Learning, Model, Strategies, Technology

\begin{abstract}
Abstrak
Model adalah bagian dari struktur pembelajaran yang memiliki cakupan yang luas. Di dalamnya terdapat pendekatan, strategi, metode, dan teknik. Salah satu aspek penting dari sebuah model pembelajaran adalah sintaks, yang merupakan langkah-langkah baku yang harus ditempuh dalam implementasi model tersebut. Sintaks ini seharusnya tercermin dalam langkah-langkah pembelajaran khususnya yang dirinci dalam kegiatan inti pembelajaran. Hasil yang dicapai dalam kegiatan ini adalah guru memiliki kemampuan mengembangkan skenario atau langkah-langkah inti pembelajaran aktif yang menggunakan model pembelajaran tertentu melalui pemanfaatan media penunjang dalam kegiatan belajar mengajar
\end{abstract}

Kata Kunci: Pembelajaran, Model, Strategi Teknologi

\section{PENDAhUluan}

Model adalah bagian dari struktur pembelajaran yang memiliki cakupan yang luas. Di dalamnya terdapat pendekatan, strategi, metode, dan teknik. Salah satu aspek penting dari sebuah model pembelajaran adalah sintaks, yang merupakan langkah-langkah baku yang harus ditempuh dalam implementasi model tersebut. Sintaks ini seharusnya tercermin dalam langkah-langkah pembelajaran khususnya yang dirinci dalam kegiatan inti pembelajaran. Dalam mengembangkan Rencana Pelaksanaan Pembelajaran (KPP) atau SAP (Satuan Acara Pembelajaran) yang meniatkan implementasi satu model pembelajaran tertentu, seharusnya aktivitasGuru mencerminkan sintaks model pembelajaran yang dipilih, demikian juga, aktivitas siswa seharusnya mencerminkan bagaimana perilaku dan model interaksi yang dipersyaratkan. Guru sebagai pengembang SAP seharusnya memiliki pemahaman yang memadai tentang model-model pembelajaran sehingga implementasinya dalam proses pembelajaran tepat dan tujuan pembelajaran bisa tercapai secara efektif. Pada sesi ini peserta akan berlatih untuk mengembangkan model dalam pembelajaran aktif di Sekolah. Secara khusus peserta akan banyak berlatih untuk mengembangkan model pembelajaran kooperatif. Disadari benar bahwa model kooperatif memerlukan perencanaan yang matang agar menjadi sebuah pembelajaran yang bermakna dan efektif. 


\section{METODE PELAKSANAAN}

Dalam pelaksanaan metode pembelajaran disekolah terdapat beberapa metode yang digunakan dalam hal pelaksanaan kegiatan belajar mengajar yaitu:

1. Pengantar

2. Diskusi dengan model kooperatif tipe TPS

3. Diskusi kelompok model kooperatif tipe jigsaw

4. Penutup

\section{HASIL DAN PEMBAHASAN}

Model pembelajarn yang dapat diterapkan dalam kegiatan belajar mengajar yaitu:

1. Pengantar

Fasilitator menjelaskan tujuan dan mekanisme sesi.

2. Diskusi dengan model kooperatif tipe TPS

a. Fasilitator menyampaikan topik bahasan yang akan didiskusikan

b. Fasilitator selanjutnya meminta tiap peserta memikirkan masalah yang mereka hadapi dan menyiapkan diri untuk berdiskusi tentang masalah yang dihadapi tersebut.

c. Fasilitator meminta setiap peserta mencari pasangan untuk membahas masalah yang mereka hadapi dan penyelesaian yang mungkin ditempuh. Setiap peserta cukup diminta memilih pasangan peserta lain yang duduk berdekatan dengannya.

d. Fasilitator selanjutnya mengarahkan semua peserta berdiskusi secara bersama-sama dengan memulai dari satu peserta yang mengemukakan masalahnya.

e. Fasilitator meminta sejumlah perwakilan pasangan untuk menyajikan hasil diskusi mereka.

f. Fasilitator menyimpulkan dan memberi penjelasan tentang model pembelajaran yang baru saja disimulasikan.

3. Diskusi kelompok model kooperatif tipe jigsaw

a. Fasilitator membagi peserta ke dalam beberapa kelompok awal yang beranggotakan 8 orang.

b. Fasilitator membagikan materi model-model pembelajaran aktif (penjelasan tentang 8 model pembelajaran aktif). Setiap anggota setiap kelompok diminta menangani satu model pembelajaran.

c. Fasilitator mengarahkan setiap peserta dengan model pembelajaran yang sama berkumpul menjadi kelompok ahli dan mendiskusikan model yang mereka tangani.

d. Fasilitator meminta setiap anggota kelompok ahli kembali ke kelompok awal mereka dan menyampaikan hasil diskusi mereka selama berada di kelompok ahli.

e. Fasilitator meminta anggota kelompok yang lain untuk tidak hanya mendengar penjelasan tersebut, tetapi juga membahasnya untuk mencapai pemahaman bersama yang tepat.

f. Fasilitator membagikan Lembar Kegiatan kepada setiap peserta dalam kelompok awal.

g. Fasilitator meminta beberapa kelompok awal untuk mempresentasikan hasil diskusi. Sebaliknya, satu kelompok diminta menjelaskan paling banyak dua model pembelajaran saja dan satu skenario (berupa Langkah

h. langkah kegiatan inti pembelajaran) yang telah dikembangkan. Model berikutnya bisa diberikan kepada kelompok berikutnya untuk dijelaskan melalui presentasi. 


\section{Penutup}

a. Fasilitator memberi penjelasan tambahan untuk memantapkan pemahaman para peserta tentang model-model pembelajaran dan bagaimana menerapkannya dalam proses pembelajaran.

b. Fasilitator meminta beberapa peserta mengemukakan pertanyaan dan membahasnya sepanjang waktu masih memungkinkan.

c. Fasilitator mengakhiri sesi dengan menanyakan kepada peserta ketercapaian tujuan sesi.

Dalam penerapan model pembelajaran jigsaw fasilitator harus dapat menjadi konektor kepada siswa dalam pelaksanaan kegiatan belajar mengajar di setiap sesi seperti pada Gambar 3.1.

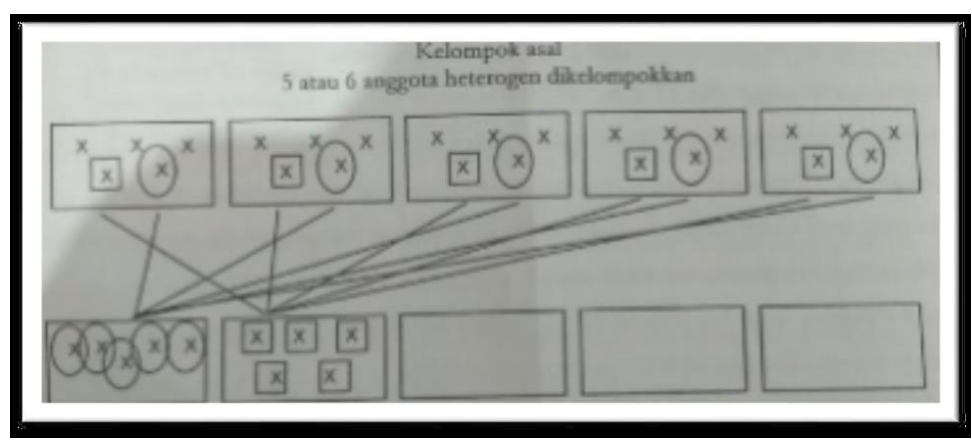

Gambar 3.1 Ilustrasi yang menunjukkan Tim Jigsaw

\section{Gambaran Umum}

Dalam pembelajaran ini, berbagai materi disajikan kepada siswa dalam bentuk teks, dan setiap siswa dalam kelompok bertanggung jawab mempelajari saatu porsi materi. Anggota tim yang berbeda dan memiliki materi sama berkumpul membentuk tim ahli untuk belajar dan saling membantu mempelajari materi tersebut. Mereka lalu kembali ke kelompok awal dan menjelaskan sesuatu yang telah mereka pelajari dalam pertemuan tim ahli.

Langkah pembelajaran yang menerapkan Model Pembelajaran Kooperatif Tipe Jigsaw :

1. Siswa dikelompokkan ke dalam 4 anggota tim.

2. Tiap orang dalam tim diberi bagian materi yang berbeda.

3. Anggota dari tim yang berbeda yang telah mempelajari bagian/sub bab yang sama bertemu dalam kelompok baru (kelompok ahli) untuk mendiskusikan sub bab mereka.

4. Setelah selesai diskusi sebagai tim ahli tiap anggota kembali ke kelompok asal dan bergantian mengajar teman satu tim mereka tentang sub bab yang mereka kuasai dan tiap anggota lainnya mendengarkan dengan sungguhsungguh.

5. Tiap tim ahli mempresentasikan hasil diskusi pada angggota di kelompok awal Guru memberi evaluasi

\section{KESIMPULAN}

Pemanfaatan teknologi informasi dalam media pembelajaran dapat memberikan dampak positif dalam kegiatan belajar mengajar di sekolah yaitu Menarik minat belajar siswa dan meningkatkan pemahaman siswa Sekolah Menengah Pertama, Dapat digunakan sebagai alat bantu bagi guru dalam menyampaikan materi secara menarik, efektif dan efisien, baik waktu dan tenaga.Media pembelajaran juga dapat digunakan bersama-sama, baik dikelas atau di pelajari secara mandiri. Disamping itu pemanfaatan teknologi yang baik di sekolah dapat meningkatkan mutu Pendidikan dalam segi efektifitas pembelajaran sehingga dapat meningkatkan mutu pendidikan di tingkat Sekolah Menengah Pertama. 


\section{UCAPAN TERIMAKASIH}

Penulis mengucapkan terima kasih kepada LPPM USU melalui dana Non PNBP Universitas Sumatera Utara sesuai dengan Surat Perjanjian Penugasan Pelaksanaan Pengabdian Kepada Masyarakat Program IBKIK Tahun Anggaran 2017 Nomor : 3223/UN5.2.3.2.1/PPM/2017, Tanggal 24 Juli 2017.

\section{DAFTAR PUSTAKA}

Stahl F, Ashworth SH, Jandt KD, Mills RW. Light-emitting diode (LED) polymerization of dental composites: flexural properties and polymerization potential. J Biomater 2000; 21 : 1379-85.

Beattie, S., 2005, Active Teaching Strategis, Baker College.

Kaufman, D. Sutow, E. \& Dunn, K., Three Approaches to Cooperative Learning in Higher Education, The Canadian Journal of Higher Education, Vol. XXVII, No. 2,3 p. 37-66

Ledlow, S., 1999, Cooperative Learning in Higher Educational, Centre for learning and Teaching Excellence, Arizona State University

Keyser, M. W., Active learning and cooperative learning: understanding the difference and using both styles effectively, Research Strategics, Vol. 17, p. 35-44

Ragains, P. 1995., Four variations in Drueke's active learning paradigm. Research strategies 13 (Winter), 40-50

Suherman, E. dkk. 2003. Strategi Pembelajaran Aktif Kontemporer. Bandung. Universitas Pendidikan Indonesia 